\title{
Study on the Thermal Environment Inside a Fully-Enclosed Subway Noise Barrier
}

\author{
Lei Liu ${ }^{1}$, Lianghan Zhang ${ }^{1}$, Zhongxu $\mathrm{Kang}^{2 *}$, and Kun $\mathrm{Yao}^{2}$ \\ ${ }^{1}$ Beijing Urban Construction Design \& Development Group Co., Limited, 100037 Beijing, China \\ ${ }^{2}$ Beijing Municipal Institute of Labour Protection, 100054 Beijing, China
}

\begin{abstract}
The thermal environment inside a fully-enclosed subway noise barrier shall be designed according to underground section tunnel standards. This article constructs a model using practical examples, simulates calculations on fully-enclosed noise barrier installations both with and without air vents via a threedimensional numerical simulation method, and then conducts a comparative analysis of the effects noise barrier lengths and air vent widths have on an internal thermal environment. The calculation results show that when the length of the fully-enclosed noise barrier without air vents was $100 \mathrm{~m}$, the internal thermal environment exceeded the limit; as the width of the air vents increased, the temperature in the internal environment gradually decreased, but the reduction was less once the air vent width exceeded $2 \mathrm{~m}$; When the top air vent width was $2 \mathrm{~m}$, and the noise barrier length was $100 \mathrm{~m}$, the thermal environment was found to meet requirements. As the noise barrier length increased, the internal air temperature exceeded the standards by varying degrees.
\end{abstract}

\section{Background}

A fully-enclosed noise barrier is the best measure for controlling noise pollution in elevated sections in the subway, where noise can be reduced by more than $20 \mathrm{~dB}$ ${ }^{[1-5]}$. Once the fully-enclosed noise barrier is applied, the elevated section can form a closed space with only two ends of it directly connected with the atmosphere, which is similar to an underground section tunnel. Therefore, internal thermal environmental controls shall be considered. However, research on noise barriers both at home and abroad focus on aspects of predictive noise reduction theory, structural dynamics, acoustic materials, and landscape design. No in-depth studies have been conducted on thermal environments fully enclosed inside noise barriers.

The thermal environment problem in a fully-enclosed noise barrier is a complex physical problem that is coupled with multiple physical phenomena, such as heat radiation, heat transfer, and flow. It is also an engineering problem with a complex structural form, making it difficult to conduct calculations directly using theoretical methods. Therefore, according to this problem's characteristics, this research introduced a three-dimensional numerical simulation calculation method based on computational fluid dynamics (CFD) ${ }^{[6,7]}$, utilizing practical projects as examples, and researched the thermal environment in a fully-enclosed subway noise barrier.

\section{Subway Thermal Environment Requirements}

Taking an elevated section of a subway project in East China as an example, this line is equipped with a fullyenclosed noise barrier over $8 \mathrm{~km}$, the maximum continuous length is $1310 \mathrm{~m}$, and the local ambient temperature is $34.5{ }^{\circ} \mathrm{C}$ in the summer.

The objective for designing this thermal environment inside fully-enclosed noise barriers is for the highest average temperature during the hottest month and day in the underground section of the tunnel to not exceed $40{ }^{\circ} \mathrm{C}$, and the most unfavorable point on the top of the train to be lower than $45^{\circ} \mathrm{C}$, ensuring that the train airconditioning condenser can operate without malfunctioning ${ }^{[8,9]}$.

The elevated sections of the subway shall adopt natural ventilation to ensure a thermal environment. In cases of a fully-enclosed noise barrier, the best solution for natural ventilation is to establish inlet and exhaust vents both on the train's top and bottom. The air flow for ventilation could be created by the difference in densities of internal and external air generated by internal heat gain. However, from the perspective of noise control, the number of openings along the noise barrier should be reduced as much as possible. At the same time, in combination with the requirements for firefighting and smoke extraction, the openings for ventilation and smoke extraction shall be provided at the top of the fully-enclosed noise barrier.

\footnotetext{
*Corresponding author: kangzhongxu@163.com
} 
Different from underground section tunnels, the primary heat gain source in an elevated fully-enclosed noise barrier is heat transfer of the enveloping structure, which is determined by two factors - solar radiation and temperature difference inside and outside of the noise barrier. The primary main factor is solar radiation heat gain.

\section{Calculation Model}

\subsection{Physical and discrete models}

The models were formed separately according to a case lacking air vents in a fully-enclosed noise barrier and a case with air vents at the top of a fully-enclosed noise barrier. Considering that the temperature and flow fields were barely affected by cables, brackets, tracks, and other factors thinw the noise barrier, the model can be simplified to the structure shown in Fig.1.

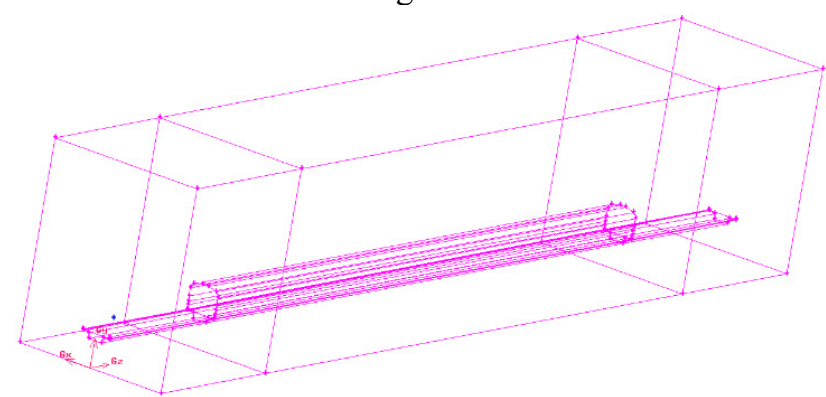

Fig.1. Overall Model Structure

The calculation domain in the model is divided into internal and external noise barrier sections. The width of the external calculation domain is 5 times that of the noise barrier, and its height is 7 times that of the noise barrier, with about $50 \mathrm{~m}$ of space on both sides of the entrance and exit to the noise barrier. Presently, the influence the external space exerts on the internal heat and flow field tends to be stable.

Geometric discretization was conducted for the structural model. In order to improve accuracy and efficiency, hexahedral elements were used for discretization. The boundary layer was encrypted near the noise barrier wall. The element size at the encryption point was about $10 \mathrm{~cm}$. In other positions along the model, the discretized size was appropriately enlarged. The number of meshes along the entire model varied with the noise barrier length is over 2 million.

\subsection{Calculation model}

Throughout researching, solar radiation intensity would be described with the solar radiation model in the CFD threedimensional numerical simulation program. Latitude and longitude were set according to the project's location, and the selection time was 2:00 pm in mid-July due to the strong solar radiation at this time, and solar radiation during clear weather was set at the same time. The model was set to the east-west direction, and the direct solar radiation intensity reaching the ground was $858.6 \mathrm{~W} / \mathrm{m}^{2}$, scattered radiation intensity on the vertical plane was 96.3 $\mathrm{W} / \mathrm{m}^{2}$, scattered radiation intensity on the horizontal plane was $116.4 \mathrm{~W} / \mathrm{m}^{2}$, and the ground reflection and scattering intensity was $87.3 \mathrm{~W} / \mathrm{m}^{2}$.

When considering solar radiation, radiation heat transfer should also be considered. The noise barrier for this project was made of soundproof materials, such as acrylic plates with excellent light transmission properties. Therefore, the DO radiation model is used in the calculation. The DO model used a gray belt model to calculate. It could calculate both gray body radiation and non-gray body radiation, while also considering the transparency characteristics of materials, such as glass.

In addition, the calculation model shall include the effects from gravity and lifting effects that result from temperature differences.

The air medium uses incompressible gas, and the buoyancy term caused by the temperature difference was considered via the Boussinesq hypothesis. The SIMPLE algorithm was used to solve the equations. While calculating, the residual error was $10^{-3}$, and the physical quantity was stable in terms of convergence criterion.

\subsection{Heat gain source and simplification}

The primary heat gain factors inside the fully-enclosed noise barrier included:

1) Heat transfer from the enveloping structure caused by solar radiation and temperature difference;

2) Heat release from train personnel and equipment through the train air-conditioning condenser;

3) Heat converted from energy loss in the train traction system;

4) Heat transfer from inside and outside air convection caused by train piston wind.

Taking the fully-enclosed noise barrier with a length of $200 \mathrm{~m}$ as an example, according to the literature ${ }^{[10]}$, heat release from the train air-conditioning condenser was $325.6 \mathrm{~kW}$. Taking the train speed as $72 \mathrm{~km} / \mathrm{h}(20 \mathrm{~m} / \mathrm{s})$, and 20 pairs of trains scheduled per hour, thus, heat release from the train air-conditioning condenser in this noise barrier section was $36.2 \mathrm{~kW}$, which was two magnitudes lower than that of the solar radiation heat gain, which could be ignored. When the train was running normally, the energy loss from the traction system was one to two magnitudes lower than that of the air-conditioning condenser ${ }^{[11,12]}$, which could also be ignored. The internal air temperature of the noise barrier was higher than the external environment, and the piston wind from the subway could promote heat dissipation. Conservatively, they could be considered unfavorable conditions, namely that the convection heat transfer caused by the piston wind could be ignored, and the effect of that piston wind should be ignored when researching.

Therefore, based on the above simplifications, the research assumed that the thermal environment in the fully-enclosed noise barrier could only gain heat from solar radiation.

\section{Simulation Results without Air Vents}


A thermal environment in a $100 \mathrm{~m}$-long fully-enclosed noise barrier without air vents should be examined. The simulation results are shown in Fig.2-5.

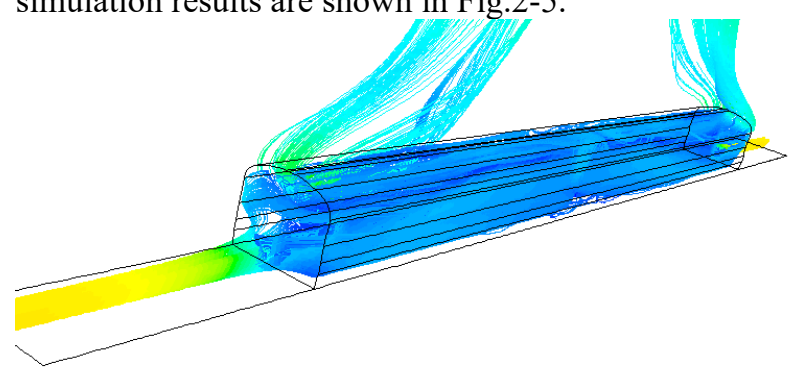

Fig.2. Streamline Diagram I inside the noise barrier
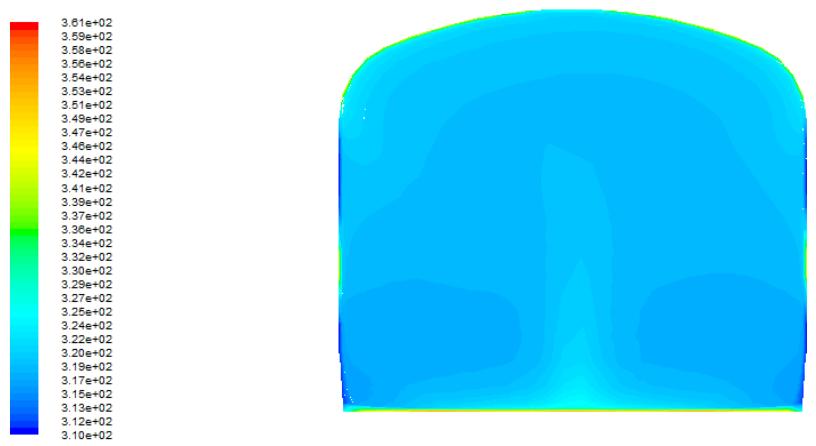

Fig.3. Central Cross-Section Temperature Cloud Diagram I inside the noise barrier Unit: $\mathrm{K}$

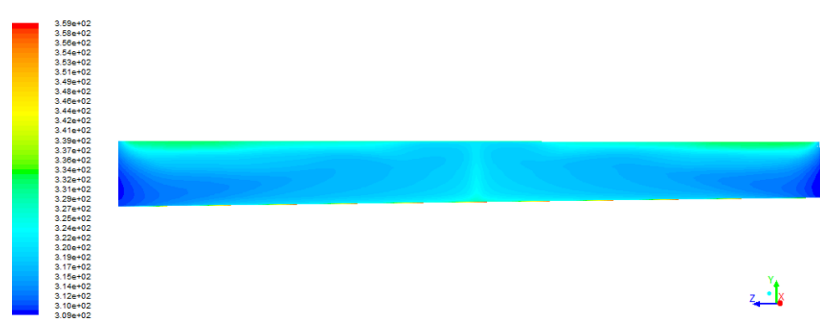

Fig.4. Central Longitudinal Section Temperature Cloud Diagram I inside the noise barrier Unit: K
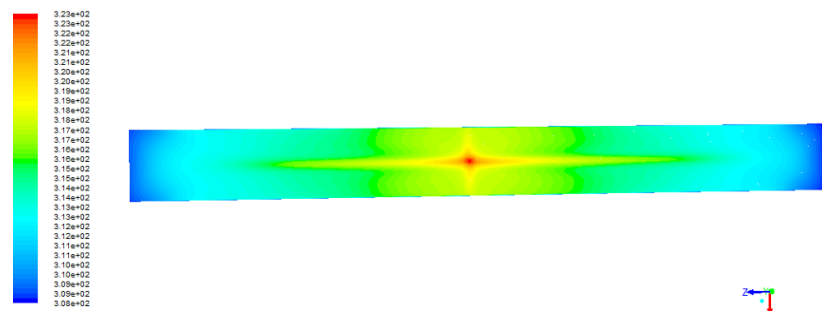

Fig.5. Plane Temperature Cloud Diagram I at the Same Height of the Train Air-conditioning Air Inlet Unit: K

The average temperature at the central position in the noise barrier was $47.1{ }^{\circ} \mathrm{C}$, the average temperature at a position $25 \mathrm{~m}$ away from the central position was $44.1{ }^{\circ} \mathrm{C}$, and the average temperature at a position $45 \mathrm{~m}$ away from the central position (i.e. near the terminal) was $42.5{ }^{\circ} \mathrm{C}$, all of which exceeded the section cross temperature limit of $40{ }^{\circ} \mathrm{C}$. The most unfavorable point was the position at the same height of the air-conditioning air inlet on the top of the train. It could be observed an area in the middle exceeded the limit of $45^{\circ} \mathrm{C}$.

Without air vents, non-compliance in terms of temperature in the noise barrier was obvious. When the length of the noise barrier was increased, the noncompliance phenomenon would inevitably become more prominent. It could be observed that it was necessary to provide a fully-enclosed noise barrier with air vents.

\section{Simulation Results in the Case with Air Vents on Top of the noise barrier}

\subsection{Air Vents $2 \mathrm{~m}$ Wide on Top of the noise barrier}

When the length of the fully-enclosed noise barrier was $200 \mathrm{~m}$ with air vents $2 \mathrm{~m}$ wide on the top, the simulation results were shown in Fig. 6-9.

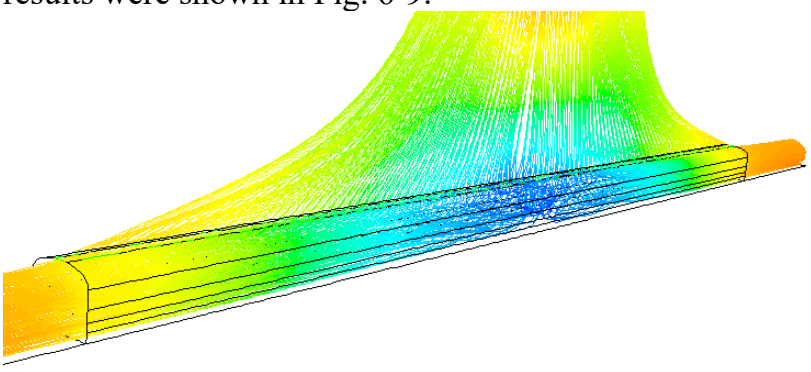

Fig.6. Streamline Diagram II inside the noise barrier
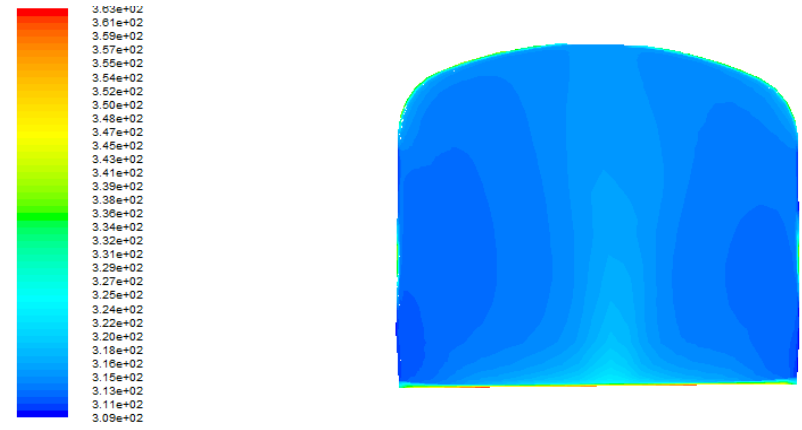

Fig.7. Cross-Section Temperature Cloud Diagram II inside the noise barrier Unit: K

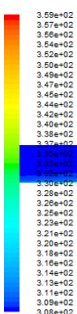

Fig.8. Central Longitudinal Section Temperature Cloud Diagram II inside the noise barrier Unit: K 

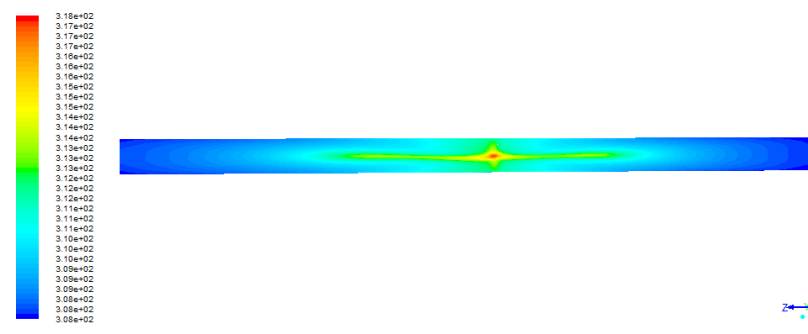

Fig.9. Plane Temperature Cloud Diagram II at the Same Height of the Train Air-Conditioning Air Inlet Unit: K

Results showed that the ambient air entered from both ends of the noise barrier and rose upward through the top opening. The temperature at both ends of the noise barrier was lower, and the air velocity was higher, but the direction was fundamentally horizontal. There was less moving air, and the temperature in the middle was higher. The air velocity was little, the movement direction was upward, and there was more stagnant air. After the air temperature in the noise barrier rose, the density would decrease and rise upward. The ambient cold air was replenished from both ends to the inside of the noise barrier. The replenished amount of cold air was greater at both ends, in the center less so, which caused the temperature at the end to be low and the middle high.

The highest temperature was near the center of the noise barrier, as shown in Fig.7, due to solar radiation absorption, the temperature of the orbital plane and the wall surfaces of the transparent material rose significantly, which caused the air temperature air in the noise barrier to rise. Among them, the effect of the orbital plane was relatively great, and the temperature decreased as height increased, except for in the vicinity of the two side wall surfaces. The average temperature of the section was 41.3 ${ }^{\circ} \mathrm{C}$, which exceeded the limit for the average temperature of $40{ }^{\circ} \mathrm{C}$. However, it could be seen from Fig. 8 that the temperature only in the short length range near the center of the noise barrier was higher, and the temperature on both sides decreased rapidly. The length where the temperature exceeding the limit was $13 \mathrm{~m}$. The temperature at the most unfavorable point was shown in Fig.9. The temperature in the noise barrier gradually rose from both ends to the center. The highest temperature in the section at the center point was $44.5{ }^{\circ} \mathrm{C}$, which was lower than the limit of $45{ }^{\circ} \mathrm{C}$.

\subsection{Influence analysis of air vent width}

Simulation calculations shall be conducted separately for the noise barrier thermal environment scheme with air vents $1 \mathrm{~m}, 2 \mathrm{~m}, 3 \mathrm{~m}$ and $4 \mathrm{~m}$ wide, and the length of the noise barrier shall be $100 \mathrm{~m}$ and $200 \mathrm{~m}$. The results are shown in Table 1 and Table 2.

Table 1. Average cross-section temperatures for different air vent width schemes Unit: ${ }^{\circ} \mathrm{C}$

\begin{tabular}{|c|c|c|c|c|}
\hline $\begin{array}{c}\text { Opening } \\
\text { width }\end{array}$ & $\begin{array}{c}\text { 100m } \\
\text { noise } \\
\text { barrier }\end{array}$ & $\begin{array}{c}\text { Width } \\
\text { exceeding } \\
\text { the limit }\end{array}$ & $\begin{array}{c}\text { 200m } \\
\text { noise } \\
\text { barrier }\end{array}$ & $\begin{array}{c}\text { Width } \\
\text { exceeding } \\
\text { the limit }\end{array}$ \\
\hline $1 \mathrm{~m}$ & 40.8 & About $3 \mathrm{~m}$ & 42.4 & About $28 \mathrm{~m}$ \\
\hline $2 \mathrm{~m}$ & 39.4 & - & 41.2 & About $13 \mathrm{~m}$ \\
\hline
\end{tabular}

\begin{tabular}{|c|c|c|c|c|}
\hline $3 \mathrm{~m}$ & 39.2 & - & 41.0 & About $8 \mathrm{~m}$ \\
\hline $4 \mathrm{~m}$ & 38.6 & - & 40.8 & About $3 \mathrm{~m}$ \\
\hline
\end{tabular}

From Table 2, it can be seen that the $1 \mathrm{~m}$ opening scheme in the $200 \mathrm{~m}$ noise barrier had a $28 \mathrm{~m}$-long area exceeding the limit; while in the $2 \mathrm{~m}$ opening scheme, the length of area exceeding the limit was only $13 \mathrm{~m}$, which was only about half a carriage's length. The length of area exceeding the limit was shorter in the other schemes. Table 2 showed the highest temperature at the most was an unfavorable point in different schemes. The results showed that the temperature at the most unfavorable points in most schemes did not exceed the $45{ }^{\circ} \mathrm{C}$ limit, and only the $1 \mathrm{~m}$ opening design with a $200 \mathrm{~m}$ noise barrier exceeded the limit by $0.6{ }^{\circ} \mathrm{C}$. The area exceeding the limit was small and would not affect the train's operation; As the width of the opening increased, the highest temperature at the most unfavorable point gradually decreased, and the reduction was also larger between $1 \mathrm{~m}$ and $2 \mathrm{~m}$, and the decreasing range became smaller once the opening was more than $2 \mathrm{~m}$.

Table .2. The Highest Temperature for Different Opening Width Schemes Unit: ${ }^{\circ} \mathrm{C}$

\begin{tabular}{|c|c|c|}
\hline $\begin{array}{c}\text { Opening } \\
\text { width }\end{array}$ & $\begin{array}{c}\text { 100m noise } \\
\text { barrier }\end{array}$ & $\begin{array}{c}\text { 200m noise } \\
\text { barrier }\end{array}$ \\
\hline $1 \mathrm{~m}$ & 44.7 & 45.6 \\
\hline $2 \mathrm{~m}$ & 43.4 & 44.5 \\
\hline $3 \mathrm{~m}$ & 42.9 & 44.5 \\
\hline $4 \mathrm{~m}$ & 42.6 & 44.4 \\
\hline
\end{tabular}

\subsection{Influence analysis of noise barrier length}

When the width of the air vent was set as $2 \mathrm{~m}$, changed the length of noise barrier used for calculation from $100 \mathrm{~m}$ to $400 \mathrm{~m}$, the results are shown in Table 3.

Table. 3. Temperature Results at Different noise barrier Lengths Unit: ${ }^{\circ} \mathrm{C}$

\begin{tabular}{|c|c|c|c|}
\hline Length & $\begin{array}{c}\text { The highest } \\
\text { average } \\
\text { temperature in } \\
\text { the cross } \\
\text { section }\end{array}$ & $\begin{array}{c}\text { Width } \\
\text { exceeding } \\
\text { the limit }\end{array}$ & $\begin{array}{c}\text { The highest } \\
\text { temperature at } \\
\text { the condenser } \\
\text { inlet }\end{array}$ \\
\hline $100 \mathrm{~m}$ & 39.4 & - & 43.4 \\
\hline $200 \mathrm{~m}$ & 41.2 & About $13 \mathrm{~m}$ & 44.5 \\
\hline $300 \mathrm{~m}$ & 43.6 & About $42 \mathrm{~m}$ & 46.4 \\
\hline $400 \mathrm{~m}$ & 41.8 & $\begin{array}{c}\text { About } 10 \mathrm{~m} \\
\text { (two } \\
\text { positions) }\end{array}$ & 44.2 \\
\hline
\end{tabular}

The results showed that as the length of the noise barrier increased, the highest average temperature of the cross section increased. When the length was $300 \mathrm{~m}$, the average temperature was the highest, exceeding the limit of $3.6{ }^{\circ} \mathrm{C}$, and the length of the area exceeding the limit was longer, about two carriages' length. However, when the length of the noise barrier increased to $400 \mathrm{~m}$, the cross-section temperature peak values were separated, 
the peak value decreased, and the length of area exceeding the limit correspondingly reduced, with each about $10 \mathrm{~m}$, similar to two $200 \mathrm{~m}$ noise barriers connected together. The highest temperature at a height of $1.8 \mathrm{~m}$ also increased with the increase of the length. Only when the length was $300 \mathrm{~m}$, the temperature exceeded the limit by $1.4{ }^{\circ} \mathrm{C}$, and when the length was changed to $400 \mathrm{~m}$, the highest temperature decreased to the level of the $200 \mathrm{~m}$ length scheme. See Fig. 10 and Fig.11 for the calculation results of the $400 \mathrm{~m}$ long noise barrier.

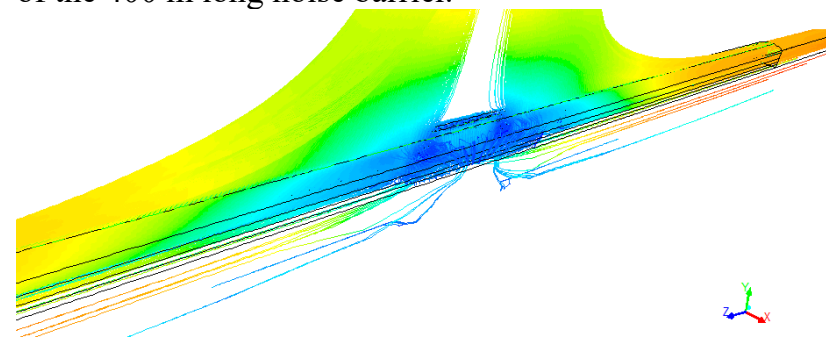

Fig.10. Streamline Diagram III inside the noise barrier

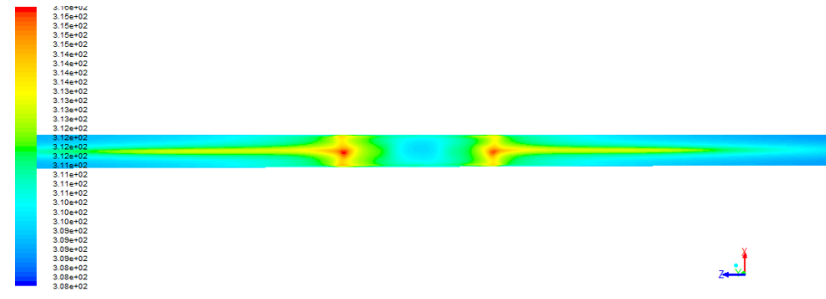

Fig.11. Plane Temperature Cloud Diagram III at the Same Height of the Train Air-conditioning Air Inlet Unit: K

\section{Analysis and Conclusion}

Taking a practical project as an example, research on the thermal environment inside the fully-enclosed noise barrier was conducted based on the CFD threedimensional numerical simulation method and the following conclusions were obtained:

The phenomenon of limit-exceeding temperatures are noticeable when the length of the fully-enclosed noise barrier without air vents is $100 \mathrm{~m}$.

The temperature near the center of the fully-enclosed noise barrier with air vents on the top is higher, while the temperature on both sides is lower. As the width of the opening increases, the temperature inside the noise barrier decreases. As the length of the noise barrier increases, the temperature inside the noise barrier rises. The temperature peak value of the cross section divided into two, and the highest temperature would decrease once the length exceeded $300 \mathrm{~m}$.

The cross section average temperature in the scheme with a 1m-wide air vent has more difficulties in conformity. After the length increases, areas over the limit appear with even more severe nonconformity once the length reaches $300 \mathrm{~m}$. Although areas over the limit exist when the length is $200 \mathrm{~m}$ or $400 \mathrm{~m}$, its length is less than that of a carriage. The temperature at the most unfavorable point of the scheme with $2 \mathrm{~m}$-wide opening and $300 \mathrm{~m}$ noise barrier exceeds the limit, while other length schemes do not exceed the limit.
As far as the practical design is concerned, the noise barrier noise control requirements shall be considered. It is a necessity to comprehensively consider the air vent layout of the fully-enclosed noise barrier in terms of firefighting and smoke extraction requirements. Protecting the overall environment around the subway as well as the internal small environment are both crucial to operations.

\section{References}

1. Li Xiaozhen, Yang Dewang, Zheng Jing, et al. Review on Vibration and Noise Reduction of Rail Transit Bridges [J] China Journal of Highway and Transport, 2018, 31(7): 55-71.

2. Yang Dewang. Research on Noise Reduction Effect of Fully-enclosed noise barrier on High-speed Railway Bridge [D]. Chengdu: Southwest Jiaotong University, 2018.

3. Tang Jian. Research on Vibration and Structuralborne Noise Prediction of U-beam Bridge in Urban Rail Transit and its Key Parameters Influence Study [D]. Chengdu: Southwest Jiaotong University, 2018.

4. Li Xiaozhen, Yang Dewang, Gao Wei, et al. Study on Vibration and Noise Reduction of Semi-or FullyEnclosed Noise Barriers of High-Speed Railways [J]. Noise and Vibration Control, 2018, Z1:8-13.

5. Ma Na. Design of Fully-closed Noise Barrier in Shanghai Rail Transit Line 6 [J] Modern Urban Transit, 2010, (5): 38-39.

6. Wang Fujun. Analysis on the Computational Fluid Dynamics: Principles and Applications of CFD Software [M]. Beijing: Tsinghua University Press, 2004:125.

7. Cheng Xiuhua, Mao Hanping, Wu Delin, et al. Numerical Simulation of Thermal Profiles in Spatial and Temporal Field for Natural Ventilated Glasshouse [J]. Transactions of the Chinese Society for Agricultural Machinery, 2009, 40 (6): 179-183.

8. Ministry of Housing and Urban-Rural Development of the People's Republic of China, State Administration for Market Regulation. GB/T 513572019 Ventilation, Air Conditioning and Heating Design Standards for Urban Rail Transit [S]. Beijing: China Architecture \& Building Press, 2019.

9. Ministry of Housing and Urban-Rural Development of the People's Republic of China, General Administration of Quality Supervision, Inspection and Quarantine of the People's Republic of China. GB 50157-2013 Code for Design of Metro [S]. Beijing: China Architecture \& Building Press, 2014.

10. Ouyang Qin, Jiang Yong, Zhu Yingxin, et al. Study on the critical ventilation speed in the blocking condition of the subway tunnel section (I) [J]. Metro and Light Rail, 2002, 56(2): 34-40.

11. United State Department of Transportation. Subway environmental design handbook[M]. Washington DC, 1978 . 
12. Zhong Xingcan. Analysis and Estimation of Air Conditioning Loads in Underground Railway [J].
Journal of $H V \& A C, 2006,36(6):$ 72-76. 